\title{
COMPORTAMENTO LEGISLATIVO DAS DEPUTADAS FEDERAIS BRASILEIRAS: UMA ANÁLISE DA PRODUÇÃO LEGISLATIVA DE 1987 A 2007
}

\author{
Geissa Cristina Franco ${ }^{1}$
}

\section{Resumo}

Uma das formas de compreender a representação substantiva das mulheres na política é através da atividade legislativa de deputadas federais. Nesse sentido, o artigo tem como objetivo analisar a produção de todas deputadas federais brasileiras eleitas que propuseram matérias legislativas entre 1987 a 2017, observando quantas proposições essas legisladoras aprovaram, quais as temáticas das matérias produzidas e aprovadas e avaliando em que medida as parlamentares produziram temas voltados às mulheres e sobre qual assunto. Trata-se de uma pesquisa descritiva, na qual foi realizada uma coleta de dados no site da Câmara Federal. Verificou-se que as parlamentares produziram 4.661 matérias legislativas e aprovaram 158, sendo que a maior produção legislativa está nos temas sociais e a maior taxa de aprovação está nos temas honoríficos, seguido dos temas políticos. A maior taxa de aprovação em temas sociais corresponde aos achados sobre produção legislativa de mulheres parlamentares tanto no Brasil como outros países como Estados Unidos.

Palavras-chave: Representação substantiva; Produção Legislativa; temática das proposições legislativas; Deputadas Federais.

\begin{abstract}
One way to understand the substantive representation of women in politics is through the legislative activity of federal women deputies. In this sense, the article aims to analyze the legislative production of all elected Brazilian federal women deputies who proposed legislative matters between 1987 and 2017, noting how many legislative proposals they approved, which themes were the legislative matters produced and approved and evaluating to what measures parliamentarians' women produced themes aimed at women and on which subject. This is a descriptive research, in which data was collected through the website of the Federal Chamber. The parliamentarians' women produced 4,661 legislative articles and approved 158, with the highest legislative production being on social topics and the highest approval rate on honorary topics, followed by political topics. The highest rate of approval on social issues corresponds to the findings on the legislative production of women parliamentarians both in Brazil and in other countries such as the United States.
\end{abstract}

Keywords: Substantive representation; Legislative Production; thematic of legislative proposals; Federal Deputies Women.

\section{Resumen}

Una forma de entender la representación sustantiva de las mujeres en la política es a través de la actividad legislativa de las diputadas federales. En este sentido, el artículo tiene como objetivo analizar la producción legislativa de todas las diputadas federales brasileñas electas que propusieron materias legislativas entre 1987 y 2017, observando cuántas propuestas legislativas aprobaron las parlamentarias federales, qué temas

\footnotetext{
${ }^{1}$ Doutoranda pelo programa de Ciência Política da Universidade Federal do Paraná, geissa_franco@hotmail.com
} 
fueron producidos y aprobados, los asuntos legislativos y evaluando en qué medidas las parlamentarias produjeron temas dirigidos a las mujeres y sobre qué tema. Se trata de una investigación descriptiva, en la que se recopilaron datos a través del sitio web de la Cámara Federal. Las parlamentarias elaboraron 4.661 artículos legislativos y aprobaron 158, siendo la mayor producción legislativa en temas sociales y la mayor tasa de aprobación en temas honoríficos, seguida de temas políticos. La mayor tasa de aprobación en temas sociales corresponde a los hallazgos sobre la producción legislativa de parlamentarias tanto en Brasil como en otros países como Estados Unidos.

Palabras Clave: Representación sustantiva; Producción legislativa; temática de propuestas legislativas; Diputados Federales.

\section{INTRODUÇÃO}

Dentro da área das Ciências Sociais há estudos que buscam entender a maior representação das mulheres na política. Dentre as diversas formas de estudar esse objeto, é possível observar o processo anterior à chegada das mulheres nos cargos eletivos, como por exemplo, o recrutamento feminino dentro dos partidos, o sistema eleitoral e a lei de cotas. Nesses estudos, o objetivo é avaliar as motivações que levam à sub-representação das mulheres na política (MANSBRIDGE, 1999). Essas pesquisas se enquadram como sendo as de representação descritiva ${ }^{2}$.

Uma outra abordagem é avaliar a atuação das mulheres já nas instituições políticas, observando o desempenho delas nesses espaços institucionais e sua influência na arena decisória (LOVENDUSKI; NORRIS, 2003). Essas pesquisas se enquadram como as de representação substantiva. É sobre a segunda vertente que o presente trabalho foi desenvolvido, tendo como foco a Câmara Federal do Brasil e as proposições legislativas de autoria das deputadas federais entre 1987 à 2017.

Nessa perspectiva de compreender a produção legislativa das deputadas federais, coloca-se como problema de pesquisa: em que medida houve ou não alterações no teor (nos temas) das proposições apresentadas pelas deputadas e no teor das proposições aprovadas por elas no decorrer das oito diferentes legislaturas entre 1987 a 2017?

Algumas pesquisas já apontaram a produção legislativa de parlamentares mulheres, correlacionando com a produção legislativa dos homens, como a de Michelle Taylor-Robson e Roseanna Heath (2003), que observou a atuação legislativa do(a)s parlamentares hondurenhos questionando se havia uma agenda legislativa diferente entre o gênero masculino e o feminino.

\footnotetext{
2 As mulheres, ao serem eleitas, estão representando o grupo de mulheres, visto que fazem parte do grupo "mulheres". Isso se chama representação descritiva. Quando as parlamentares além de representarem o grupo das mulheres no parlamento por serem mulheres, também produzem matérias legislativas para o eleitorado de mulheres passam a representar substantivamente o grupo, exercendo uma representação substantiva (PITKIN. 1967).
} 
Um dos resultados encontrados foi que as mulheres possuem $24 \%$ mais chance de produzirem proposições legislativas na temática de mulheres $^{3}$ do que os homens.

Outras investigações cientificas observaram se o aumento no número de mulheres no parlamento está conectado às chances de elas passarem mais proposições legislativas (GERMAIN, 1989; BRATTON, 2005). Não há uma resposta precisa para essa pergunta, mas Bratton (2005) aponta que as mulheres têm mais interesse em produzir sobre a temática de mulheres do que os homens, e que ocupar posições de liderança no parlamento está mais relacionada à seniority (experiência no parlamento) do que à variável 'gênero do(a) parlamentar'.

A presente pesquisa se enquadra dentro dessas perspectivas (TAYLOR-ROBSON; HEATH, 2003; GERMAIN, 1989; BRATTON, 2005), já que trataremos sobre a produção legislativa das parlamentares. Através dos estudos que avaliam o comportamento legislativo dessas mulheres, é possível medir a atuação parlamentar feminina individualmente, bem como observar como elas atuam em prol das mulheres por meio de matérias legislativas que beneficiam a esse grupo (SAINT-GERMAN, 1989; THOMAS, 1991; BRATTON, 2005; FRANCHESCHET, PISCOPO, 2008).

A metodologia que será empregada neste estudo descritivo possui cunho quantitativo e qualitativo (sem testes de hipótese). Quantitativo na medida em que há a coleta da produção legislativa das deputadas federais, em um recorte de 30 anos, com um total de 4.661 proposições legislativas. Qualitativo, pois são interpretadas as temáticas dos projetos de autoria das deputadas federais, utilizando como método a análise de conteúdo temático-categorial (BARDIN, 2011; OLIVEIRA, 2008). Essa análise se refere a diferentes técnicas que têm como objetivo descrever os conteúdos vistos nas mensagens. Por meio dela, o(a) pesquisador(a) consegue perceber indicadores que lhe mostram determinadas inferências sobre o texto analisado (BARDIN, 2011).

O trabalho está divido em três seções. A primeira seção corresponde à parte teórica, na qual buscaremos apontar como a literatura brasileira e internacional apresentam a representação das mulheres na política. Já na segunda seção, apontaremos a classificação das temáticas das proposições legislativas, bem como os dados sobre a produção legislativa nesse recorte de 1987 a 2017, mostrando a relação dos dados com o que a literatura sobre o comportamento legislativo do(a)s parlamentares já apresentou. Por fim, a última seção apresenta algumas considerações com possíveis caminhos de estudo dentro da área de representação política das mulheres.

\footnotetext{
${ }^{3}$ Não há um consenso na literatura sobre o que seria agenda legislativa que verse sobre o direito das mulheres. Geralmente, os trabalhos enquadram temas sobre mulheres as proposições legislativas que versam sobre infância, família, e temas voltados a pautas que digam respeito especificamente às mulheres, como por exemplo aborto, câncer de mama ou de colo de útero, violência contra a mulher (THOMAS, 1991; SAINT-GERMAN, 1989).
} 


\section{AS MULHERES NO PROCESSO DECISÓRIO E SUA AGENDA LEGISLATIVA}

Tratar sobre a atividade legislativa de parlamentares mulheres remete à compreensão da representação política das mesmas. Hannah Pitkin (1967), em sua obra, apresenta o ponto de partida para entender a diferença entre a representação descritiva e a representação substantiva. Para ela, há legisladoras que são eleitas, visto que representam descritivamente suas eleitoras (representação descritiva), já outras legisladoras atuam substantivamente em prol dos interesses do grupo de mulheres (representação substantiva) (PITKIN, 1967). Susan Franceschet e Jennifer Piscopo (2008) apresentam que há uma percepção analítica que conecta automaticamente a representação descritiva com a substantiva, na qual o fato de ser uma legisladora mulher significa necessariamente que a mesma irá representar os interesses das mulheres enquanto grupo e que as parlamentares terão interesses políticos similares. Essa perspectiva faz com que se reforcem noções universais do que é ser mulher, e por isso vem sendo relativizada (FRANCHESCHET; PISCOPO, 2008).

A representação substantiva pode ser vista como um processo, quando as mulheres mudam a agenda legislativa, e pode também ser entendida como resultado, no momento em que as legisladoras femininas têm sucesso em passar leis de direito para mulheres ou outras proposições legislativas de forma geral (FRACHESCHET; PISCOPO, 2008).

Partindo da perspectiva de que não podemos definir as mulheres em apenas uma forma de ser (FRANCESCHET; PISCOPO, 2008), é preciso apontar o debate da interseccionalidade cunhada por Kimberle Crenshaw ${ }^{4}(1989 ;$ 1991). A interseccionalidade estrutural surge dentro do movimento negro e busca apontar que as opressões sofridas por mulheres negras são diferentes das sofridas por mulheres brancas (CRENSHAW, 1991). Esse fator é visto na maneira como as políticas públicas, mesmo aquelas pensadas por um viés feminista, impactam em alguns casos de forma negativa sobre as mulheres negras. Certas políticas públicas necessitam ser pensadas com um olhar específico para a realidade de uma grande parte das mulheres negras, mas não são (CRENSHAW, 1989). Quando pensamos nas múltiplas opressões, como por exemplo, racismo, preconceito de classe e sexismo, não devemos criar uma adição entre essas opressões, e sim observar como a opressão de classe é racializada, como o racismo é entendido dentro do debate de gênero e assim por diante. Ou seja, observar a conexão entre essas opressões. Um exemplo

\footnotetext{
${ }^{4}$ Estamos descrevendo processos de mulheres que podem ou não atuar em agendas para o grupo de mulheres, e por isso, é necessário levar em conta que mulheres mesmo estando em um mesmo grupo possuem diferentes especificidades.
} 
disso é entender como as mulheres negras são estigmatizadas enquanto pobres e o quanto as mulheres brancas não são (CRENSHAW; 1989; 1991).

Outro ponto que devemos mencionar é que as mulheres possuem menos tempo para atuarem na política, já que dedicam um tempo maior às tarefas domésticas e cuidado com os filhos do que os homens, no caso brasileiro. Além disso, muitas mulheres não se sentem qualificadas para disputarem uma eleição, tendo como resultado o número menor de candidaturas femininas (ALMEIDA; LUCHMANN; RIBEIRO, 2012). Somadas a isso, existem as barreiras impostas pelos partidos políticos no acesso a recursos financeiros que são distribuídos de forma desiguais entre homens e mulheres (GATTO; THOME, 2020).

Os partidos políticos têm uma grande relevância quando se busca entender a sub-representação das mulheres na política. Dimensões internas como a maneira em que os partidos recrutam as parlamentares, bem como a ideologia partidária dessas agremiações também possuem um impacto no número maior de mulheres eleitas (ARAÚJO; ALVES, 2007). A literatura aponta que os partidos de esquerda tendem a ampliar a maior número de mulheres nas eleições (NORRIS; INGLEHART, 2003). Outro ponto é que partidos que possuem regras mais claras e com uma vida partidária mais constante, tendem a oferecer um maior acesso e maior atuação de mulheres (ARAÚJO, 2005).

Após a barreira inicial de entrada no parlamento, as mesmas mulheres necessitam de reconhecimento dos parlamentares e, principalmente, das lideranças partidárias para que, depois de terem alcançado uma cadeira no Parlamento, possam ser indicadas para ocupar lugares de destaque nas estruturas internas, como na Mesa Diretora e nas presidências de comissões permanentes, e assim fortalecer seu capital político (ALMEIDA; LUCHMANN; RIBEIRO, 2012, p. 113).

Tratar a respeito das agendas sobre mulheres não é uma prerrogativa exclusiva das parlamentares, visto que pode haver parlamentares do gênero masculino ${ }^{5}$ interessados também em propor mudanças, construindo agendas que pensem no direito das mulheres. No entanto, a instituição molda a atuação do(a)s parlamentares em uma determinada direção. Podemos confirmar essa análise no caso do parlamento britânico, em que os partidos limitam a atuação das parlamentares, não permitindo que as mesmas tenham certa autonomia legislativa quando votam determinadas matérias legislativas (NORRIS, 1996).

\footnotetext{
${ }^{5}$ Um artigo produzido por Barnello e Bratton (2011) observou como os parlamentares homens estadunidenses atuavam em produção legislativa na área de infância e mulheres. Um dos achados foi que há maiores mudanças substantivas com aprovação de políticas públicas nessas áreas quando os homens participam em conjunto com as mulheres nessas agendas.
} 
Os partidos possuem grande relevância no presidencialismo de coalizão, na medida em que as decisões no Congresso sofrem grande influência da atuação dos colégios de líderes, que produzem a agenda legislativa e distribuem as vagas nas comissões (SANTOS; BORGES, 2018). É necessário refletir sobre a forma de alocação dos recursos, pois a forma como ela é feita permite identificar se, e em que medida há desigualdade de gênero no legislativo brasileiro e em que medida (REZENDE, 2017).

Além das barreiras para entrar no ambiente decisório, outro diferente obstáculo se refere ao grau de poder que elas possuem na esfera de decisão dentro dos partidos, e o quanto isso implica na permanência nesse ambiente. As mulheres, além de encontrarem obstáculos na porta de entrada da Câmara dos Deputados muito maiores que os dos homens, também encontram dificuldade em ocupar postos-chave que são estratégicos para uma melhor atuação dessas parlamentares na instituição política do legislativo (BUSANELLO; REHBEIN, 2017).

Sobre a atuação das deputadas federais nas comissões permanentes no período 1995 a 2010, é possível notar que as parlamentares foram sobre representadas em oito comissões, sendo elas - Educação, Legislação Participativa, Desenvolvimento Urbano, Direitos Humanos e Minoria, Desenvolvimento Urbano, Segurança Pública e Combate ao Crime Organizado, Seguridade Social e Família. Já nas demais comissões, é possível observar que o número de parlamentares nesses espaços é menor que o percentual médio das parlamentares na Câmara (REZENDE, 2017).

Nas Comissões de Constituição e Justiça e Finanças e Tributação, que são relevantes no processo decisório, já que emitem pareceres sobre a continuidade ou não de uma determinada proposição legislativa, é possível observar que as mulheres não compuseram, de 1995 a 2010, nem $5 \%$ daqueles espaços. Há certas comissões que não foram presididas por mulheres, como a de Desenvolvimento Econômico, Fiscalização Financeira e Controle, Constituição e Justiça, Agricultura, Meio Ambiente, Minas e Energia, Trabalho, Administração e Serviço Público e Viação e Transporte. A comissão em que as mulheres foram presidentes por mais vezes foi a de Educação e Cultura, sendo um total de quatro mandatos, a segunda colocação foi a de Defesa do Consumidor, Seguridade Social e Família e Amazônia e Integração em que as mulheres ocuparam a presidência por três mandatos (REZENDE, 2017).

Um dos achados sobre ocupação de cargos em comissão encontrados por Rezende (2017, p.1212) é que

A participação das legisladoras como presidentes de comissão se concentra nas comissões cujas jurisdições incluem temas relativos ao cuidado: as comissões de Seguridade Social e Família, Educação e Cultura e Direitos Humanos e Minorias 
compreendem a quase metade das vezes em que as legisladoras presidiram comissões (9 em 21 ou 42,85\%).(REZENDE, 2017, p. 1212).

Para algumas perspectivas teóricas, as mulheres atuam mais em temáticas sociais devido às influências psicossociais desenvolvidas ao longo da vida (TAYLOR-ROBSON; HEATH, 2003). As mulheres e os homens têm diferentes experiências em suas trajetórias. Por isso, no mercado de trabalho, e no ambiente da política, mais especificamente na arena legislativa, as mulheres geralmente optam por uma agenda legislativa voltada ao cuidado (TAYLOR-ROBSON; HEATH, 2003).

Estudos que observaram a produção legislativa de parlamentares mostraram que, de modo geral, ao serem eleitas elas tendem a ter uma agenda legislativa mais voltada a áreas de educação, bem-estar social e infância (SAINT-GERMAN, 1989; THOMAS, 1991; BRATTON, 2005; TAYLOR-ROBSON; HEATH, 2003). Além disso, o aumento no número de mulheres no parlamento não significa necessariamente que as mesmas passam mais matérias legislativas, já que há um conjunto de variáveis mais relevantes como o tempo de atuação no legislativo e a influência que possuem dentro dos partidos (THOMAS, 1991).

Parlamentares mulheres conservadoras nos Estados Unidos tendem a ter uma atuação mais voltada às questões sobre mulheres do que os parlamentares homens progressistas (SWERS, 2002). Michele Swers (2002) aponta que as legisladoras são tratadas como representantes de "sua categoria", e por isso, há poucos motivos para esperar que elas tenham um incentivo para diminuir a atuação sobre agendas sobre mulheres.

É visto que mesmo que o comportamento distinto e o sucesso legislativo das representantes femininas não dependam necessariamente do aumento da porcentagem de mulheres na legislatura, um aumento no número de legisladoras que se concentrem em políticas relevantes para as mulheres, pode alterar os resultados das políticas (BRATTON, 2005).

Embora a pesquisa sobre os resultados das políticas seja menos abundante do que sobre o comportamento individual, alguns estudiosos encontraram evidências de que o aumento da diversidade de gênero tem o potencial de influenciar a vida cotidiana das mulheres. Por exemplo, Sarah Poggione (2004) descobriu que comissões legislativas estaduais com maior diversidade de gênero tinham maior probabilidade de aprovar benefícios de bem-estar relativamente generosos. Jocelyn Crowley (2004) descobriu que grupo minoritário de mulheres no parlamento, os tokens, podem fazer uma diferença nas políticas, e o potencial para fazer a diferença aumenta junto com o aumento no número de parlamentares nesse espaço. Da mesma forma, Kathleen Bratton e 
Leonard Ray (2002) descobriram que o aumento da representação feminina na Noruega estava associado ao aumento da provisão de creches.

Após apontar uma breve descrição sobre os estudos de representação política das mulheres, a próxima seção apresentará a análise dos dados sobre a produção legislativa das deputadas federais.

\section{A PRODUÇÃO LEGISLATIVA DAS DEPUTADAS FEDERAIS BRASILEIRAS}

A partir do método de análise temático-categorial, foram construídas oito categorias de temática sobre as proposições legislativas de autoria das deputadas federais. O assunto dos projetos gerais pode ser visto no Quadro 1.

Quadro 1 - Temática e explicação das proposições legislativas gerais

\begin{tabular}{|c|c|c|}
\hline Temática & $\begin{array}{c}\text { Explicação } \\
\text { Gestão }\end{array}$ & $\begin{array}{c}\text { Proposições legislativas que tratam sobre 'coisas públicas' como contratação de pessoal, } \\
\text { extinção de cargos, fiscalização de obras, aquisição e doação de bens púlicos, regulação } \\
\text { fundiária, criação de juizados etc. }\end{array}$ \\
\hline Honorífico & $\begin{array}{c}\text { Proposições legislativas referentes a homenagear pessoas, denominação de logradora e de } \\
\text { bem público, criação de dias nacionais. }\end{array}$ \\
\hline $\begin{array}{c}\text { Econômic } \\
\text { o }\end{array}$ & $\begin{array}{c}\text { Proposições legislativas referentes a questões que envolvem empresas nacionais ou } \\
\text { internacionais como diminuição ou aumento de impostos como o ICMS. Também sobre } \\
\text { investimento de fundos, ou direito do consumidor, criação de micro e pequenas } \\
\text { empresas por meio de crédito. }\end{array}$ \\
\hline $\begin{array}{c}\text { Orçament } \\
\text { o }\end{array}$ & $\begin{array}{c}\text { Matérias legislativas que envolve as contas públicas como destinação de recursos a nível } \\
\text { federal, estadual e municipal, limitação de despesas de parlamentares, alterações da Lei } \\
\text { Orçamentaria, contingência orçamentária }\end{array}$ \\
\hline Social & $\begin{array}{c}\text { Proposições legislativas voltadas a direito para as pessoas, como direito de minorias, } \\
\text { educação, cultura, saúde, habitação, lazer, turismo, pena de crimes, leis trabalhistas. }\end{array}$ \\
\hline Trânsito & $\begin{array}{c}\text { As matérias legislativas se referem a como diminuir o número de acidentes de pedestres, } \\
\text { melhoramento de calçadas e vias. Também sobre multas e radares. Também sobre os } \\
\text { valores de bilhetes de transporte. São proposições legislativas que tratam sobre os } \\
\text { diferentes transportes, as estradas, a trânsito das cidades e o direito dos pedestres. }\end{array}$ \\
\hline Política & $\begin{array}{c}\text { Questões que envolvam mudanças na política, como mudanças no regimento interno da } \\
\text { Câmara ou reforma eleitoral ou política, referendum, anistia. }\end{array}$ \\
\hline Meio-Amb & $\begin{array}{c}\text { Melhorias para a natureza como utilização de energias renováveis, coleta de lixo, como } \\
\text { ocupar os solos preservando o meio-ambiente, direito dos animais, recursos hídricos. }\end{array}$ \\
\hline iente
\end{tabular}

Fonte: Quadro produzido pela autora por meio do método de análise de conteúdo temático-categorial. As matérias legislativas analisadas foram coletadas no site da Câmara Federal.

O assunto das matérias legislativas sobre gênero pode ser encontrado no Quadro 3. É importante apontar que os projetos que versam sobre temática de gênero se encontram como uma subcategoria das matérias legislativas gerais, ou seja, todos os projetos gerais podem ou não 
ter uma subcategoria de projetos de gênero. Um projeto de gestão pode receber uma categoria como projeto de gênero, ou qualquer outro dos projetos gerais apresentados no Quadro 1. Assim, os projetos gerais recebem uma variável binominal a qual diz - esse projeto pode ser enquadrado ou não também como de gênero? Caso sim, são categorizados em uma das seis classificações do Quadro 3.

Quadro 2- Passos da classificação dos temas gerais e temas de gêneros

Temática Geral<smiles>C[14CH2]C</smiles>

Gestão, Honorífico, Social, Econômico, Trânsito, Política, Meio Ambiente e Orçamento

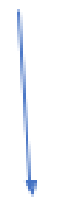

Algum desses temas pode ser subclassificado como tema de gênero também?
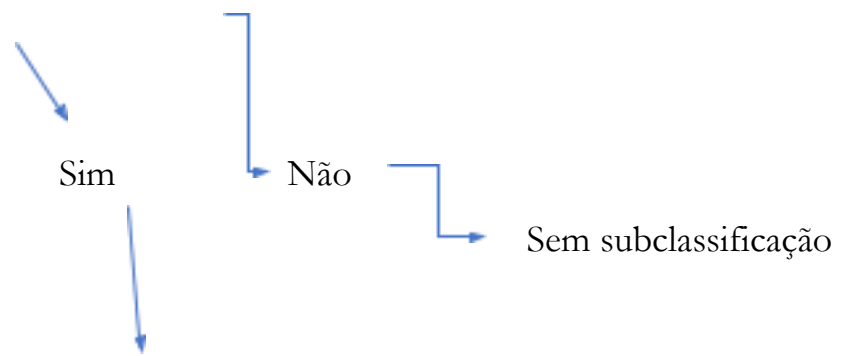

Classifica em uma das categorias - violência de gênero, maternidade, mulheres na política, orientação sexual e identidade de gênero, acesso ao mercado de trabalho e reconhecimento

Fonte: Quadro produzido pela autora.

Quadro 3 - Temática e explicação das matérias legislativas que versam sobre gênero

\begin{tabular}{|c|c|}
\hline Tema do Projeto & Explicação \\
\hline Violência de gênero & $\begin{array}{r}\text { As proposições legislativas que versam sobre os diversos tipos de } \\
\text { violência que as mulheres sofrem, sendo elas desde violência } \\
\text { doméstica até feminicídio. Um exemplo seria o aumento na pena } \\
\text { por crimes praticados contra as mulheres }\end{array}$ \\
\hline Maternidade & $\begin{array}{r}\text { Proposições legislativas que garantem direitos para as gestantes e } \\
\text { mães. Exemplos seriam aumento de licença maternidade }\end{array}$ \\
\hline Mulheres na política & $\begin{array}{c}\text { Proposições que versam sobre o maior acesso das mulheres nos } \\
\text { espaços políticos. Um exemplo seria o aumento de cadeiras para } \\
\text { as mulheres no legislativo por meio de cotas. }\end{array}$ \\
\hline $\begin{array}{c}\text { Orientação sexual e } \\
\text { identidade de gênero } \\
\text { mulheres lésbicas, bissexuais } \\
\text { e trans }\end{array}$ & $\begin{array}{r}\text { Projetos que garantem direitos para as mulheres lésbicas e } \\
\text { transêneras/travestis. Um exemplo é as mulheres trâns também } \\
\text { estarem incluídas dentro da Lei Maria da Penha. }\end{array}$ \\
\hline
\end{tabular}




\begin{tabular}{|c|c|}
\hline $\begin{array}{c}\text { Acesso ao mercado de } \\
\text { trabalho }\end{array}$ & $\begin{array}{c}\text { Proposições legislativas que retratam sobre a mulher no mercado } \\
\text { de trabalho. Um exemplo é o aumento de vaga para as mulheres } \\
\text { em empresas. }\end{array}$ \\
\hline Reconhecimento & $\begin{array}{c}\text { Matérias que versem sobre questões honoríficas } \\
\text { como datas comemorativas, nome de ruas direcionadas as } \\
\text { mulheres. Proposições legislativas que trazem reconhecimento da } \\
\text { importância das mulheres dentro da sociedade por meio de } \\
\text { nomeações de espaços ou datas específicas relacionadas as } \\
\text { mulheres. }\end{array}$ \\
\hline
\end{tabular}

Fonte: Quadro produzido pela autora de acordo com a análise de conteúdo temático-categorial realizada. As matérias legislativas analisadas foram coletadas no site da Câmara Federal.

A seguir, apresentaremos alguns dados encontrados nessa pesquisa sobre a temática das proposições legislativas das parlamentares. O corpus de análise dessa pesquisa são 4.661 proposições legislativas sendo Projetos de Lei, Projetos de Emenda a Constituição e Projeto de Lei Complementar.

Um primeiro dado apresentado no Gráfico 1 é a respeito do número de mulheres eleitas deputadas federais em cada legislatura analisada. A partir dele, observamos um aumento no número de parlamentares eleitas, apesar do percentual de deputadas não chegar a $10 \%$ do número total dos legisladores, nem ao menos na última legislatura analisada, que vai de 2015 a 2018. Se somarmos a quantidade de eleitas da legislatura 1987-1990 a 2015-2018 vemos que o total de mulheres foi de 322. Isso significa que em oito legislaturas, as deputadas não chegaram a compor a quantidade total de parlamentares por legislatura que é 513.

Gráfico 1 - Número de deputadas federais eleitas de acordo com a legislatura

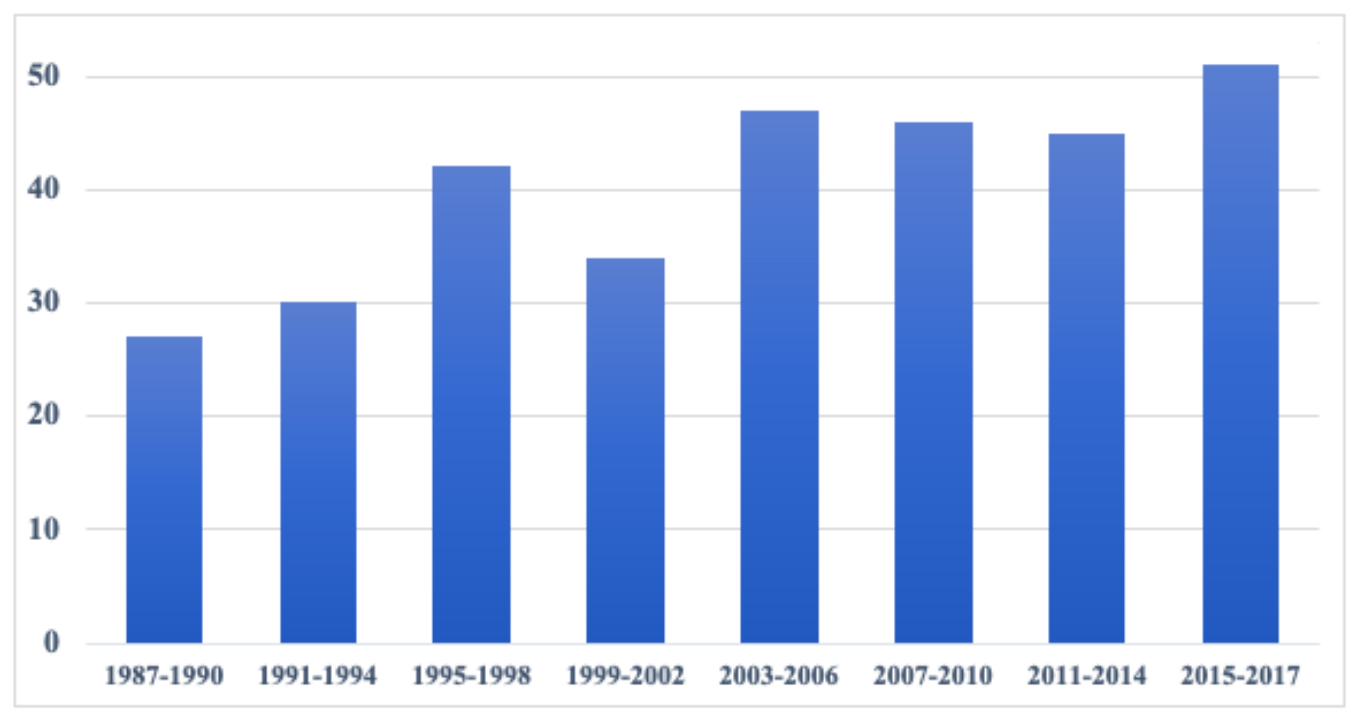

Fonte: Gráfico produzido pela autora de acordo com as informações coletadas do site da Câmara Federal. 
No Gráfico 2, é possível ver a produção legislativa das parlamentares de 1987 a 2017 por legislatura. Observamos que a produção legislativa das deputadas aumentou substancialmente ao longo das legislaturas. Uma das motivações para isso pode ser o aumento no número de deputadas eleitas nesse recorte temporal da pesquisa. Confirmaremos ou não essa ideia nas análises do Gráfico 3.

Entre 1987 a 2017, foram transformadas em norma jurídica 158 proposições de autoria das deputadas federais de um total de 4.661, esse dado nos diz que aproximadamente 3,38\% da produção das deputadas federais produzidas como autoras individuais ou em coautoria foram aprovadas. A seguir, apresentaremos a produção legislativa das deputadas federais de acordo com as temáticas dos projetos legislativos.

Gráfico 2 - Produção legislativa das deputadas federais por legislatura

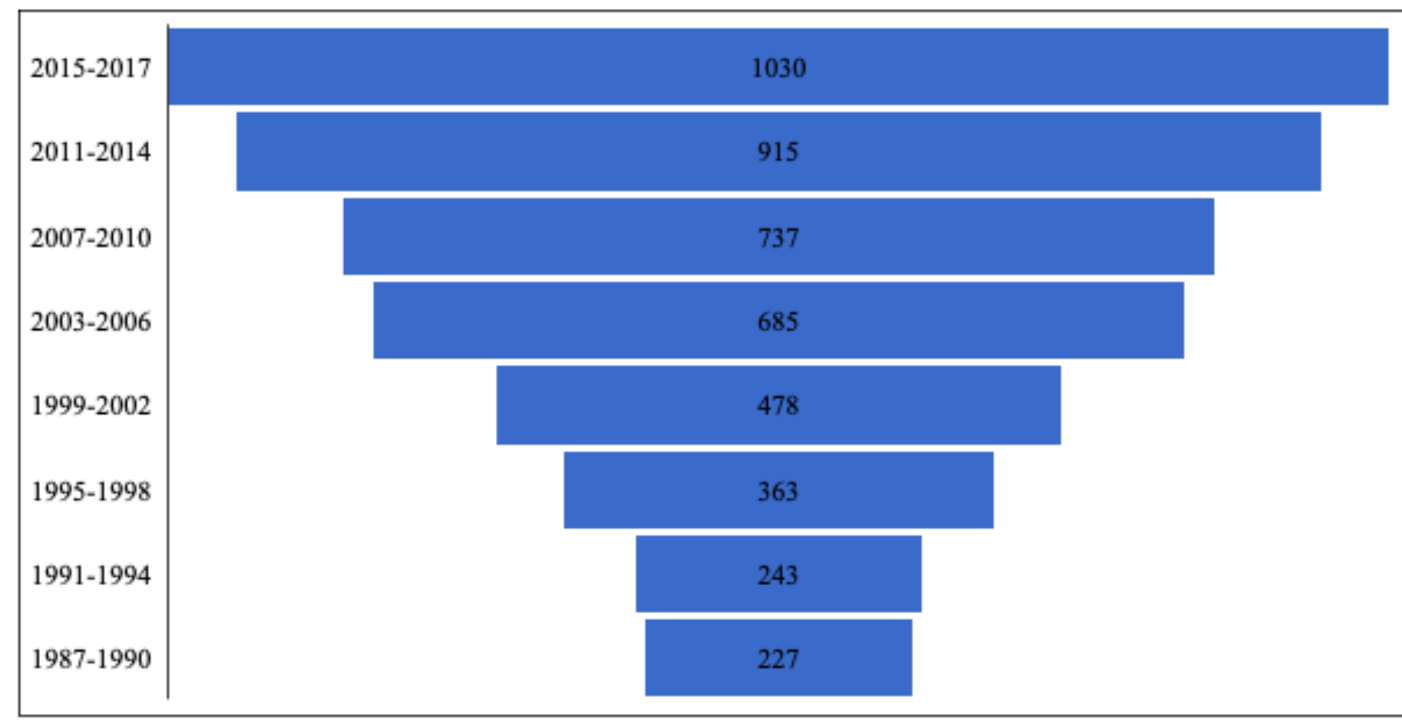

Fonte: Gráfico produzido pela autora de acordo com as informações coletadas do site da Câmara Federal

Como já mencionado, é possível observar pelo Gráfico 2 que, ao passar das legislaturas, houve um aumento no número de produção legislativa. Será que é possível dizer que o aumento no número de produção está relacionado ao aumento no número de legisladoras? Para observar isso, calculamos a média de produção legislativa por legisladora em cada legislatura, como é possível observar no Gráfico 3. 
Gráfico 3 - Média individual de matérias legislativas produzidas pelas parlamentares por legislatura

\begin{tabular}{|c|c|}
\hline 2015-2017 & 20,19 \\
\hline 2011-2014 & 20,33 \\
\hline $2007-2010$ & 16,02 \\
\hline 2003-2006 & 14,57 \\
\hline 1999-2002 & 14,05 \\
\hline 1995-1998 & 8,64 \\
\hline 1991-1994 & 8,1 \\
\hline $1987-1990$ & 8,4 \\
\hline
\end{tabular}

Fonte: Gráfico produzido pela autora de acordo com as informações coletadas do site da Câmara Federal.

Mesmo com o aumento no número de parlamentares eleitas ao passar das legislaturas, observamos que as parlamentares passaram a produzir mais proposições legislativas, especialmente a partir da legislatura 1999 a 2002.

\subsection{OS TEMAS DAS PROPOSIÇÕES LEGISLATIVAS PRODUZIDOS PELAS PARLAMENTARES}

Um dos objetivos específicos da pesquisa é saber em que temática as autoras das legislações tiveram maior poder de aprovação ${ }^{6}$. O Gráfico 4 aponta que o maior poder de aprovação das deputadas foi na temática social: em 30 anos de produção legislativa, 53,16\% do que foi transformado em norma jurídica advêm da área social.

Esse dado corresponde à produção geral das deputadas federais que pode ser vista na Tabela 1, já que das 4.661 proposições legislativas produzidas, 2.352 eram de cunho social, ou seja, 50,46\% da produção total das deputadas é na área social, sendo assim o poder de aprovação delas é maior nessa temática. As proposições legislativas de cunho social são as mais produzidas e mais se aprovadas, entretanto não são as de maior taxa de sucesso como é visto na Tabela 1.

\footnotetext{
${ }^{6}$ Nesse artigo apenas observamos a taxa de sucesso da produção legislativa das deputadas federais. Isso quer dizer que não é realizada uma comparação entre o que é produzido pelos homens e pelas mulheres.
} 
Gráfico 4 - Quantidade de proposições legislativas transformadas em norma-jurídica de acordo com a temática do projeto

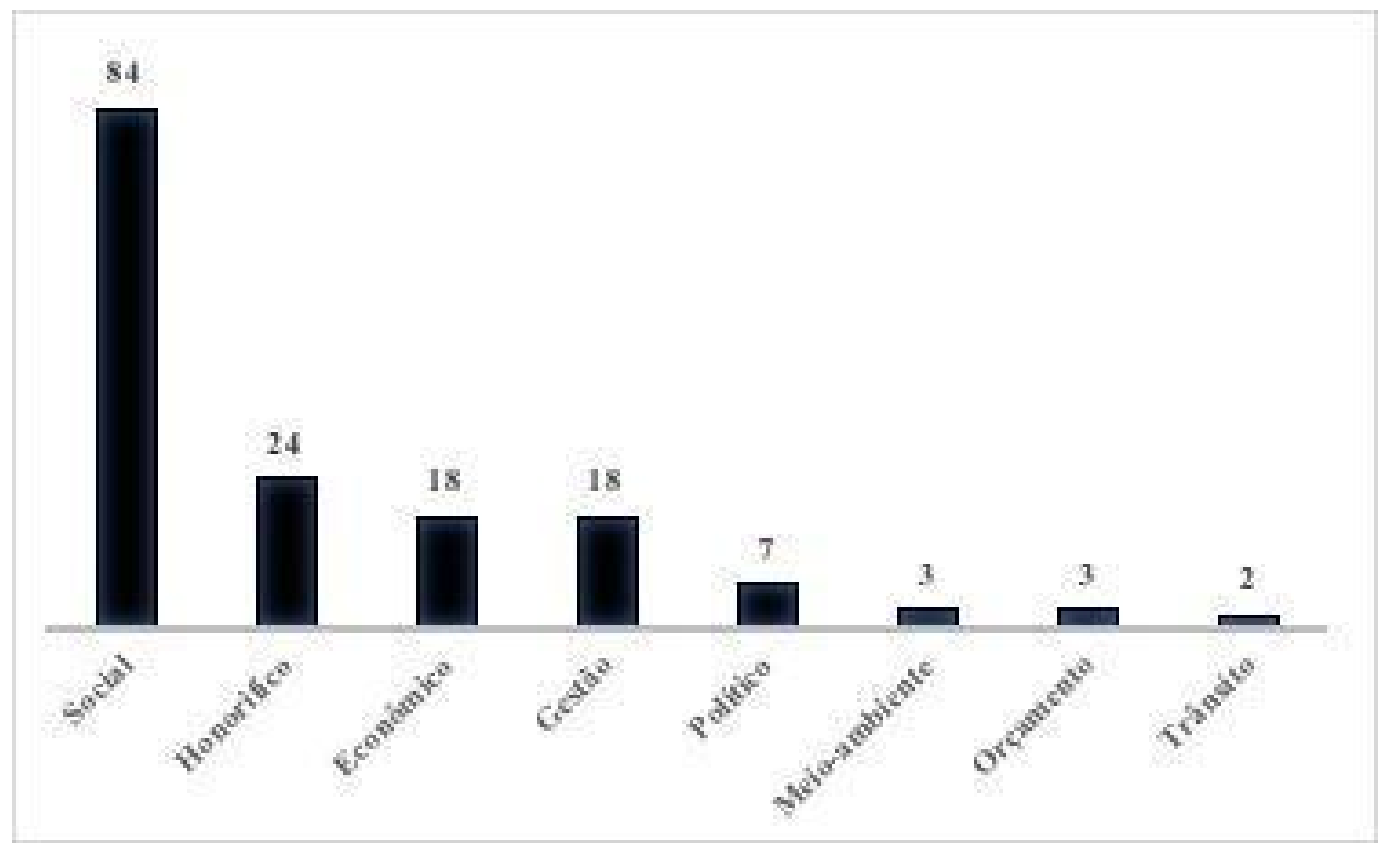

Fonte: Gráfico produzido pela autora de acordo com a coleta de dados realizada no site da Câmara Federal.

Observamos que a segunda maior produção legislativa das deputadas é na área econômica. Foram produzidas 1.010 proposições legislativas nessa temática, no entanto, a aprovação nesse grupo ficou em terceiro lugar. Projetos de temática honorífica têm maior facilidade de serem aprovados no legislativo, isso ocorre porque esse tema não trata de assuntos que trazem grandes alterações para a sociedade. Foram produzidos 181 projetos honoríficos e aprovados 24. Os dados sobre aprovação ou não das proposições de acordo com a temática estão disponíveis na Tabela 1.

Tabela 1 - Situação das proposições legislativas de acordo com a temática e taxa de sucesso por temática

\begin{tabular}{c|c|c|c|c|c|c}
\hline Temáticas & $\begin{array}{c}\text { Transformad } \\
\text { o em norma } \\
\text { jurídica }\end{array}$ & $\begin{array}{c}\text { Vetado } \\
\text { totalmente }\end{array}$ & Arquivado & $\begin{array}{c}\text { Em } \\
\text { tramitação }\end{array}$ & $\begin{array}{c}\text { Total de } \\
\text { proposiçõe } \\
\text { s de cada } \\
\text { tema }\end{array}$ & $\begin{array}{c}\text { Taxa } \\
\text { de } \\
\text { sucess } \\
\text { o }\end{array}$ \\
\hline Social & 84 & 5 & 1242 & 1021 & 2352 & $3,57 \%$ \\
\hline Econômico & 18 & 4 & 566 & 422 & 1010 & $1,78 \%$ \\
\hline Gestão & 18 & 1 & 369 & 228 & 616 & $2,92 \%$ \\
\hline Honorífico & 24 & 2 & 90 & 65 & 181 & $13,2 \%$ \\
\hline Político & 7 & 0 & 74 & 72 & 153 & $4,57 \%$ \\
\hline
\end{tabular}




\begin{tabular}{c|c|c|c|c|c|c}
\hline Trânsito & 2 & 1 & 54 & 90 & 147 & $1,36 \%$ \\
\hline $\begin{array}{c}\text { Meio-ambie } \\
\text { nte }\end{array}$ & 3 & 0 & 70 & 57 & 130 & $2,30 \%$ \\
\hline Orçamento & 2 & 0 & 41 & 29 & 72 & $2,77 \%$ \\
\hline Total & 158 & 13 & 2.506 & 1984 & 4.661 & $3,38 \%$ \\
\hline
\end{tabular}

Fonte: Tabela produzido pela autora de acordo com a coleta de dados realizada no site da Câmara Federal.

A taxa de sucesso das deputadas, nesses 31 anos, foi de 3,38\% de aprovação do total das proposições apresentadas. A partir da Tabela 1 é possível observar o desempenho político-institucional das deputadas federais em cada temática de proposições apresentadas. Para entender o desempenho político-institucional em cada agenda apresentada, é necessário saber a quantidade de projetos aprovados nessas diferentes matérias legislativas pela quantidade de projetos apresentados nas distintas proposições legislativas. Através dessa análise, podemos observar que o melhor desempenho político-institucional das deputadas em relação aos temas é na temática de projetos honoríficos e não na social como poderia ser suposto.

\subsection{A PRODUÇÃO LEGISLATIVA DAS DEPUTADAS FEDERAIS NA ÁREA DE GÊNERO}

Uma questão a ser analisada nesta pesquisa é sobre a produção das deputadas federais no que se refere à temática de gênero, sobre a qual foi construída uma tipologia dos temas das proposições legislativas (Quadro $2^{7}$ ). As deputadas produziram 401 projetos na temática de gênero. É necessário saber quantos desses foram aprovados e do que tratam esses projetos aprovados. Um ponto que chama a atenção na Tabela 2 é que há apenas um projeto que foi vetado que se relaciona a maternidade. Talvez, o número baixo de vetos presidenciais nas proposições voltadas à temática de gênero signifique que as deputadas, por terem maior expertise e background nessa área, passam a ter menor dificuldade em aprovar seus projetos.

\footnotetext{
${ }^{7}$ No quadro 2, foi construído o que se entende como temática de gênero, de acordo com o que as parlamentares brasileiras produziram em 30 anos legislativos. Realizou-se uma análise de conteúdo temático categorial para classificar as matérias legislativas (OLIVEIRA, 2008). Por isso, classificamos os projetos sobre gênero/mulheres em - violência de gênero, maternidade, orientação sexual e identidade de gênero, mulheres na política, mulheres, reconhecimento, acesso ao mercado de trabalho. É importante salientar que apontamos na parte teórica discussões sobre o que a literatura entende como tema de gênero ou tema de mulheres. Entende-se que a matéria legislativa tratará sobre direito das mulheres, quando tratar de um tema específico às mulheres como por exemplo, aborto, câncer de mama ou de colo de útero, violência contra a mulher (THOMAS, 1991; SAINT-GERMAN, 1989).
} 
É possível observar, a partir da Tabela 2, que as deputadas conseguiram aprovar ${ }^{8} 7,48 \%$ do total dos projetos enviados na temática de gênero. Isso nos diz que as parlamentares têm mais chances de aprovar matérias voltadas a temática de mulheres do que as proposições legislativas classificadas como gerais, já que conseguiram aprovar 3,38\% do que enviaram nos temas gerais. Os trabalhos estadunidenses sobre produção legislativa já apontavam que as parlamentares tendem a produzir sobre a temática de gênero ao serem eleitas, e terem maior sucesso de aprovação nessa temática (BRATTON, 2005; POGGIONE, 2004; SAINT-GERMAIN, 1989). Outras pesquisas com foco em países da América Latina também possuem resultados que vão de encontro a esses achados, como foi visto em Honduras (TAYLOR-ROBSON; HEATH, 2003) e na Argentina (FRANCESCHET; PISCOPO, 2008).

Tabela 2 - Proposições voltadas a temática de gênero e situação em que se encontram

\begin{tabular}{c|c|c|c|c|c|c}
\hline & $\begin{array}{c}\text { Arquivad } \\
\mathbf{a}\end{array}$ & $\begin{array}{c}\text { Em } \\
\text { tramitaçã } \\
\mathbf{o}\end{array}$ & $\begin{array}{c}\text { Transformad } \\
\text { a em norma } \\
\text { jurídica }\end{array}$ & $\begin{array}{c}\text { Vetada } \\
\text { totalment } \\
\mathbf{e}\end{array}$ & $\begin{array}{c}\text { Contage } \\
\text { m total }\end{array}$ & $\begin{array}{c}\text { Taxa de } \\
\text { sucesso }\end{array}$ \\
\hline $\begin{array}{c}\text { Acesso ao } \\
\text { mercado de } \\
\text { trabalho }\end{array}$ & 26 & 11 & 2 & 0 & 39 & $5,12 \%$ \\
\hline Maternidade & 56 & 33 & 8 & 1 & 98 & $8,16 \%$ \\
\hline $\begin{array}{c}\text { Orientação sexual } \\
\text { e identidade de } \\
\text { gênero- mulheres } \\
\text { lésbicas, bissexuais } \\
\text { e trans }\end{array}$ & 7 & 15 & 0 & 0 & 22 & $0 \%$ \\
\hline $\begin{array}{c}\text { Mulheres na } \\
\text { política }\end{array}$ & 13 & 14 & 1 & 0 & 28 & $3,57 \%$ \\
\hline Reconhecimento & 49 & 46 & 14 & 0 & 109 & $\mathbf{1 2 , 8 4 \%}$ \\
\hline $\begin{array}{c}\text { Violência de } \\
\text { gênero }\end{array}$ & 39 & 61 & 5 & 0 & 105 & $4,76 \%$ \\
\hline Total geral & 190 & 180 & 30 & 1 & 401 & $\mathbf{7 , 4 8 \%}$ \\
\hline
\end{tabular}

Fonte: Tabela produzido pela autora de acordo com a coleta de dados no site da Câmara Federal.

Antes de dar continuidade à análise dos dados da Tabela 2, é necessário relembrar que a construção da tipologia dos temas que versam sobre mulheres foi desenvolvida através da técnica de análise de conteúdo temático-categorial. A autora do trabalho coletou inicialmente uma

\footnotetext{
${ }^{8}$ A equação da taxa de sucesso nas matérias legislativas referentes a gênero é a quantidade de matérias aprovadas pela quantidade de matérias produzidas. Assim, foram aprovadas 30 matérias e produzidas 401 . Dividindo 30 por 401 , obtemos 0,0748 que corresponde a 7,48\%. Já os temas gerais, dividimos o total aprovado pelo total produzido, e assim temos 158 dividido por 4.661, que corresponde a 0,0338 que significa 3,38\%. Esse segundo dado está disponível na tabela 1 , junto com a taxa de sucesso obtida em todas as matérias gerais. Já o primeiro dado, está disponível na tabela 2 junto com a taxa de sucesso das distintas matérias legislativas voltadas a temática de mulheres.
} 
amostra de 50 matérias que versassem diretamente para as mulheres, observando similaridades e diferentes entre os projetos, e a partir disso, construiu as seis agendas presentes na Tabela 2. A análise de conteúdo passou pelo crivo da replicabilidade e validade ao ser desenvolvido um livro de códigos para que o coletador voluntário entendesse sobre do que se trata os temas das matérias e pudesse coletar novamente as 50 proposições legislativas coletadas anteriormente pela autora. Ao final, houve $85 \%$ de similaridade nas coletas desenvolvidas por ambos, podendo ser replicável o método utilizado.

A maior produção das deputadas é na área de reconhecimento e a maior aprovação segue essa linha, todavia, a segunda maior produção é na temática de violência de gênero, que, no entanto, encontra-se como a terceira na aprovação. As deputadas têm mais chance de aprovar proposições legislativas na temática de maternidade do que de violência de gênero. Percebemos uma produção legislativa menor em proposições legislativas voltadas para mulheres lésbicas, bissexuais e mulheres trans. Observamos também que as mulheres parlamentares produzem em menor quantidade proposições legislativas voltadas às mulheres na política, ou seja, matérias legislativas que thes beneficiam. A produção legislativa voltada ao maior acesso das mulheres ao mercado de trabalho é menor também. Analisando de uma maneira apenas quantitativa esses dados, podemos supor que as parlamentares colocam a representação das mulheres nos espaços públicos como o mercado de trabalho e na política de forma secundária nas preferências de ação. $\mathrm{E}$ as mulheres trans, bissexuais e lésbicas têm seus interesses sub representados pelas próprias parlamentares mulheres.

\subsection{UMA ANÁLISE TEMPORAL DO QUE FOI PRODUZIDO E APROVADO NA TEMÁTICA DAS MATÉRIAS LEGISLATIVAS DAS PARLAMENTARES NAS DIFERENTES LEGISLATURAS}

Esta pesquisa busca perceber se, nas diferentes legislaturas analisadas, houve mudanças ou não no que foi produzido, em termos de temática, e no que foi aprovado pelas deputadas. A maior produção legislativa delas, nas oito legislaturas estudadas, refere-se à temática social e a segunda maior produção legislativa foi na temática econômica, como vemos na Tabela 3. Percebemos que, nas diferentes legislaturas, as deputadas federais tendem a ter um padrão similar de produção legislativa: a produção na temática social é superior às outras, e mais que o dobro das matérias legislativas de cunho econômico. 
No que se refere à aprovação de projetos por separação de temática, nas oito legislaturas, observamos que a temática social teve a maior aprovação de projetos em todas as legislaturas, com um total de 84 projetos aprovados, uma média de 10,5 matérias aprovadas por legislatura, como vemos na Tabela 4. A temática econômica permanece na segunda colocação em número de projetos aprovados, no entanto, está ocupando o posto com as proposições legislativas de tema de gestão.

Tabela 3 - Produção total de proposições legislativas separadas por temática nas 8 legislaturas analisadas

\begin{tabular}{c|c|c|c|c|c|c|c|c|c}
\hline Temática & $\begin{array}{c}\mathbf{1 9 8 7 - 1} \\
\mathbf{9 9 0}\end{array}$ & $\begin{array}{c}\mathbf{1 9 9 1 - 1} \\
\mathbf{9 9 4}\end{array}$ & $\begin{array}{c}\mathbf{1 9 9 5 - 1} \\
\mathbf{9 9 8}\end{array}$ & $\begin{array}{c}\mathbf{1 9 9 9 - 2} \\
\mathbf{0 0 2}\end{array}$ & $\begin{array}{c}\mathbf{2 0 0 3 - 2} \\
\mathbf{0 0 6}\end{array}$ & $\begin{array}{c}\mathbf{2 0 0 7 - 2} \\
\mathbf{0 1 0}\end{array}$ & $\begin{array}{c}\mathbf{2 0 1 1 - 2} \\
\mathbf{0 1 4}\end{array}$ & $\begin{array}{c}\mathbf{2 0 1 5 - 2} \\
\mathbf{0 1 7}\end{array}$ & Total \\
\hline Econômico & 44 & 53 & 88 & 112 & 141 & 156 & 205 & 211 & 1010 \\
\hline Gestão & 31 & 42 & 51 & 79 & 98 & 124 & 111 & 80 & 616 \\
\hline $\begin{array}{c}\text { Meio-Ambie } \\
\text { nte }\end{array}$ & 1 & 9 & 4 & 9 & 27 & 39 & 20 & 21 & 130 \\
\hline Orçamento & 2 & 3 & 5 & 7 & 14 & 15 & 11 & 15 & 72 \\
\hline Político & 6 & 5 & 12 & 15 & 22 & 28 & 30 & 35 & 153 \\
\hline Social & 139 & 128 & 188 & 222 & 333 & 304 & 476 & 562 & 2.352 \\
\hline Trânsito & 4 & 2 & 6 & 8 & 23 & 22 & 27 & 55 & 147 \\
\hline Honorífico & 0 & 1 & 9 & 26 & 27 & 49 & 35 & 34 & 181 \\
\hline Total & 227 & 243 & 363 & 478 & 685 & 737 & 915 & 1013 & 4.661 \\
\hline
\end{tabular}

O que podemos perceber sobre produção e aprovação é que a maior produção e aprovação das deputadas é na temática social, mas elas, mesmo assim, não deixam de lado temas considerados como agenda econômica nas suas atividades legislativas. Proposições de cunho honorífico e meio-ambiente não são vistas em grande proporção.

Tabela 4 - Aprovação total das proposições legislativas separadas pelas temáticas nas 8 legislaturas

\begin{tabular}{c|c|c|c|c|c|c|c|c|c}
\hline Tema & $\begin{array}{c}\mathbf{1 9 8 7 -} \\
\mathbf{1 9 9 0}\end{array}$ & $\begin{array}{c}\mathbf{1 9 9 1 - 1} \\
\mathbf{9 9 4}\end{array}$ & $\begin{array}{c}\mathbf{1 9 9 5 - 1 9 9} \\
\mathbf{8}\end{array}$ & $\begin{array}{c}\mathbf{1 9 9 9 - 2 0} \\
\mathbf{0 2}\end{array}$ & $\begin{array}{c}\mathbf{2 0 0 3 - 2 0} \\
\mathbf{0 6}\end{array}$ & $\begin{array}{c}\mathbf{2 0 0 7 - 2 0} \\
\mathbf{1 0}\end{array}$ & $\begin{array}{c}\mathbf{2 0 1 1 - 2 0} \\
\mathbf{1 4}\end{array}$ & $\begin{array}{c}\mathbf{2 0 1 5 - 2 0} \\
\mathbf{1 8}\end{array}$ & Total \\
\hline Econômico & 0 & 0 & 2 & 4 & 4 & 3 & 4 & 1 & 18 \\
\hline Gestão & 1 & 2 & 0 & 6 & 6 & 1 & 1 & 1 & 18 \\
\hline $\begin{array}{c}\text { Meio-Ambie } \\
\text { nte }\end{array}$ & 1 & 0 & 0 & 0 & 1 & 1 & 0 & 0 & 3 \\
\hline Orçamento & 0 & 0 & 0 & 0 & 1 & 0 & 0 & 1 & 2 \\
\hline Político & 0 & 0 & 0 & 2 & 1 & 3 & 1 & 0 & 7 \\
\hline
\end{tabular}


FRANCO, G. C. Comportamento legislativo das deputadas federais brasileiras: Uma análise da producão legislativa de 1987 a 2007. DOI: http://dx.doi.org/10.5380/recp.v11i1.74468

\begin{tabular}{c|c|c|c|c|c|c|c|c|c}
\hline Social & 2 & 11 & 8 & 15 & 13 & 15 & 10 & 10 & 84 \\
\hline Trânsito & 0 & 0 & 0 & 1 & 0 & 0 & 1 & 0 & 2 \\
\hline Honorífico & 0 & 0 & 0 & 4 & 6 & 8 & 4 & 2 & 24 \\
\hline Total & 4 & 13 & 10 & 32 & 32 & 31 & 21 & 15 & 158 \\
\hline
\end{tabular}

Fonte: Tabela produzida pela autora.

Além disso, com o passar das legislaturas, as deputadas parecem ter tido um maior interesse em produzirem proposições legislativas de temas de cunho econômico e de gestão. Pode-se dizer que elas não têm grande poder de decisão nesses temas, no entanto, se identifica o interesse delas na produção de proposições legislativas nessa área.

\subsection{ANALISANDO O PODER DE AGENDA DAS PARLAMENTARES BRASILEIRAS}

Avaliando a produção legislativa das deputadas federais, vemos que elas produzem mais em áreas sociais e aprovam mais proposições legislativas em normas jurídicas também nessa área. Entre 1989 a 1998, a agenda do Executivo estava mais nos temas econômicos e administrativos e já o do Legislativo em temas sociais (FIGUEIREDO, LIMONGI, 1999). Além disso, são nos temas sociais que o legislativo tem uma maior capacidade de aprovar proposições. Esses dados também se confirmam com as deputadas federais, já que aprovam mais em temáticas sociais.

Os dados encontrados na pesquisa nos mostram que as parlamentares brasileiras produzem mais na área social. Todavia, quando avaliamos a taxa de sucesso, vemos que a primeira colocação é na temática honorífica, em segundo lugar, o tema político e, em terceiro, o tema social. Os parlamentares (homens e mulheres), de modo geral, possuem uma atuação maior em temas sociais ${ }^{9}$ se comparados a temas como orçamento, economia, administrativo, econômico, homenagem (GOMES, 2013).

Vemos pelos dados que as mulheres deputadas têm mais chance de aprovar projetos de gênero (classificação feita pela autora no Quadro 2) do que os projetos de maneira geral. Uma das hipóteses para que isso ocorra pode estar relacionada ao fato de as parlamentares serem postas em comissões mais voltadas à área social e à área de direito para mulheres, como aponta Rezende (2017), o que lhes daria uma expertise nessa área.

Ainda sobre a temática de gênero produzida pelas parlamentares, observamos que o foco maior de produção é na temática de reconhecimento, a segunda colocação é violência de gênero

\footnotetext{
${ }^{9}$ Um estudo de Borges (2013) que fez uma análise temporal de 1999 a 2006 no que se refere a produção legislativa apontou que tanto na Câmara quanto no Senado os parlamentares produzem $60 \%$ da sua produção em áreas sociais. Além disso, o próprio poder Executivo envia mais matérias legislativas na área social.
} 
e, a terceira maternidade. É interessante o fato de a primeira colocação ser na temática de reconhecimento, visto que isso nos diz que as parlamentares querem garantir maior visibilidade para as mulheres. No entanto, ao avaliar as proposições voltadas para as mulheres transgênero, lésbicas e bissexuais percebemos uma diminuição grande na quantidade produzida: apenas 22 proposições produzidas em 31 anos, e nenhuma aprovada. Na temática das mulheres na política, vemos um número menor em comparação a temática reconhecimento, já que apenas foram produzidas 28 proposições e na temática acesso ao mercado de trabalho, 39 proposições legislativas produzidas.

Durante todas as legislaturas analisadas, pudemos observar um aumento na produção legislativa de todas as temáticas. No tema que elas menos legislaram, que foi sobre orçamento, observamos um aumento de mais de sete vezes entre a primeira e a última legislatura analisada. Um questionamento que pode surgir é: mas por que isso ocorre? Pesquisas apontam que, a partir dos anos 2000, o Executivo deixou de ter uma predominância na produção legislativa e na emissão de medidas provisórias, e com isso os e as deputado(a)s passaram a produzir um maior número de proposições legislativas (FIGUEIREDO, LIMONGI, 1999; ALMEIDA, 2018). Existem explicações variadas para o porquê dessa diminuição na dominância do Executivo, como por exemplo a fragilidade do sistema partidário visto especialmente pelo número excessivo de partidos (AMES, 2001). Pode ser também pela concentração de poderes formais no presidente e nos líderes partidários (FIGUEIREDO, LIMONGI, 1999). Outro ponto é a concentração dos ministérios durante os governos petistas que piorou o desempenho da coalizão (RAILE, PEREIRA e POWER, 2010). Por fim, outra variável que pode ser observada é a proibição de reedição de medidas provisórias com a Emenda 32 de 2001.

\section{CONCLUSÃO}

A pesquisa buscou analisar a produção legislativa das deputadas federais em um recorte temporal de 30 anos. Utilizamos a perspectiva teórica sobre a representação substantiva, visto que ela é a que melhor se enquadra nessa pesquisa. Para analisar a representação substantiva das parlamentares brasileiras, observamos os temas gerais produzidos e aprovados por elas, assim como os temas sobre mulheres.

Os resultados apontam uma maior produção e aprovação em números absolutos na área social, e uma maior taxa de sucesso em projetos honoríficos. A partir desses achados, confirmamos o que a teoria sobre processo legislativo já apresentava sobre a atuação parlamentar 
dos parlamentares em geral ser em temas sociais. As deputadas federais possuem uma atividade de produção na área social, mas elas também produzem em temáticas econômicas. Delimitar a atuação delas a área social é deixar em aberto as 1010 proposições legislativas na área econômica produzidas pelas parlamentares, e as dezoito aprovadas nessa área.

Quando avaliamos a aprovação na temática de mulheres, vemos uma maior taxa de sucesso por parte das parlamentares do que quando avaliamos os temas gerais. Isso pode nos dizer que algumas mulheres buscam representar substantivamente o grupo de mulheres e conseguem ter sucesso na aprovação de temáticas sobre mulheres. Possivelmente, isso é fruto do background e da expertise no tema. Apenas um trabalho que avalie a atuação delas em comissões sobre o tema de mulheres ou a quantidade de tempo no parlamento podem confirmar esse achado.

Criar normas para a entrada das mulheres nos espaços de poder não é uma garantia de que as mesmas conseguiram atuar de forma eficaz. É necessário haver não somente uma política de ideias, mas também de presença (PHILIPS, 1995). Isso quer nos dizer que as mulheres não devem apenas pensar como mudar as estruturas sociais que as colocam em uma posição de sub-representação, mas elas devem ocupar os espaços de poder, minimamente, em número que as represente. Utilizando essa ideia de Anne Philips, acreditamos que além da política de ideia e presença, deve a haver uma politica de preparo dessas legisladoras. Por isso, as parlamentares devem ter ideias, estarem presentes, e ao entrarem nessa estrutura se sentirem preparadas para esse cargo, para que possam alcançar melhores posições no parlamento. Estudos que apresentem essas parlamentares no seu espaço de poder ajudam a encontrar mecanismos institucionais que garantam as deputadas federais maior representação.

Algumas sugestões futuras de estudos são os que examinem de forma mais detalhada -1 . A atuação das parlamentares em comissões; 2. A comparação na produção legislativa feminina com a masculina; 3. Um exame sobre a relação das parlamentares com os seus partidos como a disciplina e coesão partidária; 4.Ocupação de postos-chave dados pelos líderes partidários; 5. Uma análise sobre quem são essas parlamentares que conseguem acessar o legislativo brasileiro; 6. Estudos de produção legislativa comparada na América Latina e no mundo, observando padrões e diferenças na atuação legislativa de mulheres.

\section{REFERÊNCIAS}

ALMEIDA, C., LUCHMANN, Li., RIBEIRO, B. (2012). Associativismo e representação feminina no Brasil. Revista Brasileira de Ciencia Politica, Brasília, nº 8, p. 237-263, maio/agosto. 
ALMEIDA, A S. (2018). Governo presidencial condicionado: delegação e participação legislativa na Câmara dos Deputados. Rio de Janeiro. Tese (Doutorado em Ciência Política). IESP/UERJ.

AMES, B. (2001). The Deadlock of Democracy in Brazil: Interests, Identities, and Institutions in Comparative Politics. Ann Arbor: University of Michigan Press.

ARAÚJO, C. (2005). Partidos Políticos e Gênero: Mediações nas Rotas de Ingresso das Mulheres na Representação Política. 2005. Revista de Sociologia e Politica, Curitiba, n² 24, p. 193-21, junho.

ARAÚJO, C., ALVES, J. E. D. (2007). Impactos de Indicadores Sociais e do Sistema Eleitoral sobre as Chances das Mulheres nas Eleiç,oes e suas Interaçoes com as Cotas. Dados - Revista de Ciências Sociais, Rio de Janeiro, vol. 50, nº 3, 2007, p. 535-577, janeiro.

BARDIN, L. (2011). Análise de Conteúdo. São Paulo: Edições 70.

BARNELlO, M. A., BRATTON, K. A. (2007). Bridging the Gender Gap in Bill Sponsorship. Legislative Studies Quarterly, Washington University, vol. 32, n 3, p. 449-474, agosto.

BRATTON, K. A. (2005). Critical Mass Theory Revisited: The Behavior and Success of Token Women in State Legislatures. Politics \& Gender, Cambridge University Press, vol. 1, $\mathrm{n}^{\circ}$ 1, p. 97-125, 09 de setembro.

BRATTON, K. A., RAY, L. P. (2002). 'Descriptive Representation, Policy Outcomes, and Municipal Day-Care Coverage in Norway', American Journal of Political Science, Midwest Political Science Association, vol. 46, n 2, p. 428-37, abril.

BUSANELLO, E., REHBEIN, M. (2017). As deputadas federais na presidência e vice-presidência das comissões permanentes da Câmara dos Deputados: quem são elas e como chegaram lá? E- legis, Brasilia, nº 23, p. 106-132, maio/agosto.

CARROLL, S. J. (2001). The Impact of Women in Public Office. Bloomington IN: Indiana University Press.

CRENSHAW, K. (1989). Demarginalizing the intersection of race and sex: a black feminist critique of antidiscrimination doctrine, feminist theory and antiracist politics. University of Chicago Legal Forum, Chicago, vol. 1, nº 1, p. 139-167.

CRENSHAW, K. (1991). Mapping the Margins': Intersectionality, Identity Politics, and Violence, against Women. Stanford Law Review, vol. 43, n 6, p. 1241-99, julho.

CROWLEY, J. E. (2004). When Tokens Matter'. Legislative Studies Quarterly, Comparative Legislative Research Center, vol. 29, n 1, p. 109-36, fevereiro.

FIGUEIREDO, A C, LIMONGI, F. (1999). Executivo e Legislativo na Nova Ordem Constitucional. Rio de Janeiro: Fundação Getulio Vargas Editora.

FRANCESCHET, S., PISCOPO, J. M. (2008). Gender Quotas and Women's Substantive Representation: Lessons from Argentina. Politics \& Gender, Cambridge University Press, vol. 4, p. 393-425, setembro. 
GATTO, M. A. C., THOME, D. (2020). Resilient aspirants: Women's candidacies and election in times of Covid-19. Politics \& Gender, Cambridge University Press, vol. 16, p. 1001-1008, julho.

GOMES, F. B. C. (2013). Produção Legislativa no Brasil: Visão Sistêmica e Estratégica no Presidencialismo de Coalizão. Brasília: Câmara dos Deputados.

LOVENDUSKI, J., NORRIS, P. (2003). Westminster women: the politics of presence. Political Studies, Blackwell Publishing Ltd, vol. 51, n 1, p. 84-102, março.

MANSBRIDGE, J. (1999). Should blacks represent blacks and women represent women? A contingent "yes". The Journal of politics University of Texas Press, vol. 61, n 3, p. 628-657, agosto.

MORAES, T. P. B et.al. (2014). Mulheres, política e sub-representação. Um estudo sobre correlação entre qualidade da democracia, ideologia e mulheres no parlamento. Derecho y Cambio Social, Lima, n 36, p.1-29, 01 de abril.

NORRIS, P. (1996). Women politicians: transforming Westminster? Parliamentary Affairs, Oxford University Press, vol. 49, n 1, p.89-102, 1 de janeiro.

NORRIS, P., INGLEHART, R. (2003). Gender Equality and Cultural Change around the World. Cambridge: Cambridge University Press.

OLIVEIRA, D. C de. (2008). Análise de conteúdo temático categorial: uma proposta de sistematização, Revista de Enfermagem, Universidade Estadual do Rio de Janeiro, vol. 16, $\mathrm{n}^{\circ}$ 4, p. 569-576, outubro/dezembro.

PINHEIRO, L S. (2007). Vozes femininas na politica: uma análise sobre mulheres parlamentares no pós-Constituinte. Brasilia: Secretaria Especial de Políticas para as Mulheres.

RAILE, E. D., PEREIRA, C., POWER, T. J. (2011). The Executive Toolbox: Building Legislative Support in a Multiparty Presidential Regime. Political Research Quarterly, University of Utah, vol. 64, $\mathrm{n}^{\circ} 2$, p. 323-334, junho.

PHILLIPS, A. (1995). The Politics of Presence Oxford: Clarendon.

POGGIONE, S. (2004). Exploring Gender Differences in States Legislator's Policy Preferences. Political Research Quarterly, University Libraries, vol. 57, n² 2, p. 305-314, junho.

REZENDE, D L. (2017). Desafios à representação política de mulheres na Câmara dos Deputados. Estudos Feministas, Florianópolis, vol. 25, n 3, p. 1199-1218, setembro/dezembro.

RICCI, P. (2003). O conteúdo da Produção Legislativa Brasileira: Leis Nacionais ou Políticas Paroquiais? DADOS - Revista de Ciências Sociais, Rio de Janeiro, vol. 46, nº 4, p. 699-734.

SAINT-GERMAN, M. A. (1989). Does their difference make a difference? The impact of Women on Public Police in the Arizona Legislature. Social Science Quartely, University of Texas Press, vol. $70, \mathrm{n}^{\circ} 4$, dezembro. 
SANTOS, M. L. (2008). Teoria e Método nos estudos sobre o Legislativo Brasileiro: uma Revisão da Literatura no período 1994-2005. Revista Brasileira de Informação Bibliográfica em Ciências Sociais-BIB, São Paulo, $\mathrm{n}^{\circ}$ 66, $2^{\circ}$ semestre.

SANTOS, F., BORGES, M. (2018). Poder de agenda. Coleção Governo e Políticas Públicas. Brasília: Enap.

SWERS, M. L. (2002). The Difference Women Make: The Policy Impact of Women in Congress. Chicago: University of Chicago Press.

TAYLOR-ROBSON, M., HEATH, R. M. (2003). Do women legislators have different policy priorities than their male colleagues? Women \& Politics, Universite Laval, vol. 24, $\mathrm{n}^{\circ} 4,15 \mathrm{de}$ outubro.

THOMAS, S. (1991). The impact of women on State Legislative Policies. The Journal of Politics, University of Chicago Press, vol. 53, n 4, p. 957-976, novembro. 